\title{
Synthesis of fatty monoester lubricant base oil catalyzed by Fe-Zn double-metal cyanide complex
}

\author{
RAVINDRA K RAUT, MEHEJABEEN SHAIKH and SRINIVAS DARBHA* \\ Catalysis Division, CSIR-National Chemical Laboratory, Pune 411 008, India \\ e-mail: d.srinivas@ncl.res.in
}

MS received 15 February 2014; revised 7 April 2014; accepted 8 April 2014

\begin{abstract}
Fatty monoester lubricant base oils as high as $96.7 \mathrm{~mol} \%$ were prepared by reacting methyl oleate with long-chain alcohols viz., 2-ethyl-1-hexanol $\left(\mathrm{C}_{8}-\mathrm{OH}\right)$, 1-decanol $\left(\mathrm{C}_{10} \mathrm{OH}\right)$ and 1-dodecanol $\left(\mathrm{C}_{12} \mathrm{OH}\right)$ in the presence of a solid Fe-Zn double-metal cyanide (DMC) complex catalyst. Unlike many other acid catalysts, DMC doesn't produce undesired ether side products. The catalyst was reusable in four recycling experiments with little loss in catalytic activity and ester yield. The long-chain esters prepared in the study have the desired physical properties for their application as lubricant base oils.
\end{abstract}

Keywords. Fatty monoester; lubricant base oil; transesterification; Fe-Zn double-metal cyanide (DMC) catalyst.

\section{Introduction}

High performance, long product life and better ecological compatibility are the characteristic features that make fatty monoesters important as high quality biodegradable lubricant base oils. ${ }^{1,2}$ Unlike other synthetic oils $c a$. poly alpha-olefins (PAO) and poly alkylene glycols (PAG), the ester oils are miscible with a large number of additives to formulate effective biodegradable lubricants. Currently, more than 10,000 lubricant formulations are needed to meet the world demand of 12 billion gallons per year. ${ }^{3-5}$ Through a proper choice of fatty acid and long-chain alcohol, a wide variety of lubricants with custom design properties can be synthesized. Biodegradable lubricants reduce environmental pollution which the conventional mineral oil-based lubricants cause after their usage.

Note: about $53 \%$ of mineral oil lubricants are collected as waste endangering the planet. ${ }^{6}$

Monoesters are categorized as 'non-water pollutant' lubes which reduce the expenses of oil spillage or disposal. It is realized that more than $90 \%$ of all the current lubricants could be formulated to be rapidly biodegradable. ${ }^{6}$ The ester oils are normally for highend usage due to their higher price. Biolubricants are priced twice as high as conventional petroleum lubricants. As a consequence, only a few percentage of the market for slippery fluids is commanded by

\footnotetext{
*For correspondence
}

bio-based lubricants. ${ }^{3,7}$ They are produced by esterification of a fatty acid or transesterification of vegetable oil with a long-chain alcohol in presence of a homogeneous acid/base catalyst ${ }^{8-10}$ or by using an ionexchange resin. ${ }^{11,12}$ Their synthesis from the reaction of fatty acid methyl esters (FAME-biodiesel) and longchain alcohol is attractive, as a part of biodiesel pool, can be converted to more valuable lube product. This diversion possibly makes biodiesel production economical even in the absence of incentives from the government.

Cost effective production of synthetic esters is of utmost importance for their wider use. The homogeneous mineral acid or base catalysts currently used are non-reusable. Additional process steps are needed for catalyst neutralization and separation. Significant amount of salt and hard water is generated as waste by-product. Ion exchange resins have limited thermal stability confining their application to reactions with short chain alcohols only. Use of solid catalysts in place of homogeneous catalysts make the process attractive and cost-effective. Solid catalysts can be recyclable and processes involving them can be green and zerowaste generating. Silica-sulphuric acid, Amberlyst-15, immobilized lipase $\left(\right.$ Novozym $\left.{ }^{\circledR} 435\right)$, sulfated zirconia, calcium methoxide, titanosilicates and zirconium phenyl phosphonate phosphite are a few solid catalysts reported for biolubricants' preparation. ${ }^{13-18}$ Earlier, we reported the application of $\mathrm{Fe}-\mathrm{Zn}$ doublemetal cyanide (DMC) complex as an efficient catalyst for producing biolubrciants by transesterification of vegetable oils with linear chain monohydric $\mathrm{C}_{8}$ 
alcohol ${ }^{19}$ and esterification of oleic acid with polyhydric alcohols. ${ }^{20}$ We now extend the study reporting their use for transesterfication of methyl oleate (a component of biodiesel) with 2-ethyl-1-hexanol $\left(\mathrm{C}_{8} \mathrm{OH}\right), 1$-decanol $\left(\mathrm{C}_{10} \mathrm{OH}\right)$ and 1-dodecanol $\left(\mathrm{C}_{12} \mathrm{OH}\right)$ producing the corresponding long-chain alcohol monoesters. DMC complexes are hydrophobic and Lewis acid catalysts. ${ }^{19,20}$ The lubricant properties of the produced monoesters are reported.

\section{Experimental}

\subsection{Catalyst preparation}

DMC was prepared as reported by us earlier ${ }^{19}$ using $\mathrm{K}_{4} \mathrm{Fe}(\mathrm{CN})_{6} \cdot 3 \mathrm{H}_{2} \mathrm{O}$ as a source of $\mathrm{Fe}, \mathrm{ZnCl}_{2}$ as a source of $\mathrm{Zn}$, tert.-butanol as complexing agent and PEG-4000 as co-complexing agent. Prior to use in reactions, the DMC catalyst was activated at $180^{\circ} \mathrm{C}$ for $2 \mathrm{~h}$.

\subsection{Characterization techniques}

X-ray powder diffraction (XRD) patterns of fresh and spent DMC catalysts were recorded on a Phillips X'pert Pro diffractometer equipped with a Ni-filtered $\mathrm{Cu}-\mathrm{K} \alpha$ radiation ( $\lambda=0.15418 \mathrm{~nm}, 40 \mathrm{kV}$ and $30 \mathrm{~mA}$ ) and a proportional counter detector. The diffraction patterns were recorded in the $2 \theta$ range of $10-80^{\circ}$ with a scan rate of $4 \% \mathrm{~min}$ and with a step size of $0.02^{\circ}$. Fourier transform infrared (FTIR) spectra of the samples as $\mathrm{KBr}$ pellets $(1 \mathrm{wt} \%)$ were measured in the wavenumber range of $400-4000 \mathrm{~cm}^{-1}$ with a spectral resolution of $4 \mathrm{~cm}^{-1}$ on a Shimadzu 8300 spectrophotometer. All the other characterization studies were done as reported elsewhere. ${ }^{19,20}$ Physical properties of fatty acid monoesters were determined at Chem-Tech Laboratories Pvt. Ltd., Pune, India (Supplementary Information).

\subsection{Reaction procedure}

Methyl oleate (MO, Sigma-Aldrich Co., technical grade $70 \%$; balance $30 \%$ being methyl palmitate and stearate) was transesterified with $\mathrm{C}_{8}-\mathrm{C}_{12}$ alcohols [2ethyl-1-hexanol (Loba Chemie, 99\%), 1-decanol and 1-dodecanol (SD Fine Chem.]. In a typical reaction, $6.76 \mathrm{mmol}$ of $\mathrm{MO}$ and three equivalent excess of alcohol and $0.06 \mathrm{~g}$ of DMC catalyst (3 wt\% of $\mathrm{MO})$ were taken in a glass, round-bottom flask placed in a temperature-controlled oil bath and connected with water-cooled condenser. Temperature was raised to $180^{\circ} \mathrm{C}$ and the reaction was conducted for $8 \mathrm{~h}$ at atmospheric pressure under a flow of nitrogen. Nitrogen drives out the by-product methanol formed in the reaction and pushes the equilibrium towards the product. Then, the temperature of the reaction mixture was brought down to room temperature $\left(25^{\circ} \mathrm{C}\right)$ and the catalyst was separated by centrifugation $(\mathrm{RCF}=7000 \mathrm{~g}$ for 5 min using a Remi Laboratory Instrument, Model No. R-24)/filtraton. Excess, unreacted alcohol in the product mixture was removed by steam-distillation. The product monoester was analyzed by a Perkin-Elmer (Series 200) high performance liquid chromatography fitted with an ELSD detector (Gilson) and reverse-phase Brownlee column (C-18, Spheri-5, $250 \times 4.6 \mathrm{~mm})$. For kinetics studies, reactions were conducted at five different temperatures $(433,443,453,463$ and $473 \mathrm{~K})$ for a period of $4 \mathrm{~h}$. Rate constants were determined from the concentration verses time plots using a pseudofirst order rate equation. Arrhenius equation enabled determination of thermodynamic parameters (activation energy and Gibbs free energy). The yield of oleic fatty monoester was confirmed also by ${ }^{1} \mathrm{H}$ NMR (Bruker Avance $200 \mathrm{MHz}$ ) and gas chromatography (GC, Varian CP 3800; column - Varian CP 9079, 15 m long $\times 0.32 \mathrm{~mm}$ ID $\times 0.1$ um film thickness) techniques. It should be noted that methyl palmitate and stearates present in $\mathrm{MO}$ as impurity (30\%) have also been converted to the corresponding lube esters with equal efficiency as that of methyl oleate.

\section{Results and discussion}

\subsection{Catalyst characterization}

A detailed characterization of Fe-Zn DMC catalyst was reported by us earlier. ${ }^{19,20}$ Table 1 lists some characteristic parameters of the catalyst used in this study. DMC (molecular formula: $\mathrm{K}_{4} \mathrm{Zn}_{4}\left[\mathrm{Fe}(\mathrm{CN})_{6}\right]_{3} \cdot 6 \mathrm{H}_{2} \mathrm{O} .2$ (tert.-

Table 1. Physicochemical characteristics of Fe-Zn DMC catalyst.

\begin{tabular}{|c|c|}
\hline Physical property & Value \\
\hline Molecular formula & $\begin{array}{l}\mathrm{K}_{4} \mathrm{Zn}_{4}\left[\mathrm{Fe}(\mathrm{CN})_{6}\right]_{3} \cdot 6 \mathrm{H}_{2} \mathrm{O} .2 \\
\text { (tert.-BuOH) }\end{array}$ \\
\hline Crystal lattice & Cubic \\
\hline Unit cell parameter $(a)$ & $0.904 \mathrm{~nm}$ \\
\hline Average crystallite size & $36 \mathrm{~nm}$ \\
\hline Average particle size & $0.8 \mu \mathrm{m}$ \\
\hline Particle morphology & Cubic/spherical \\
\hline Specific surface area $\left(\mathrm{S}_{B E T}\right)$ & $52 \mathrm{~m}^{2} / \mathrm{g}$ \\
\hline Acidity & $1.96 \mathrm{~m}^{2} / \mathrm{g}$ \\
\hline IR bands & $\begin{array}{l}2925,2096,1260-1450 \\
\text { and } 1095 \mathrm{~cm}^{-1}\end{array}$ \\
\hline
\end{tabular}




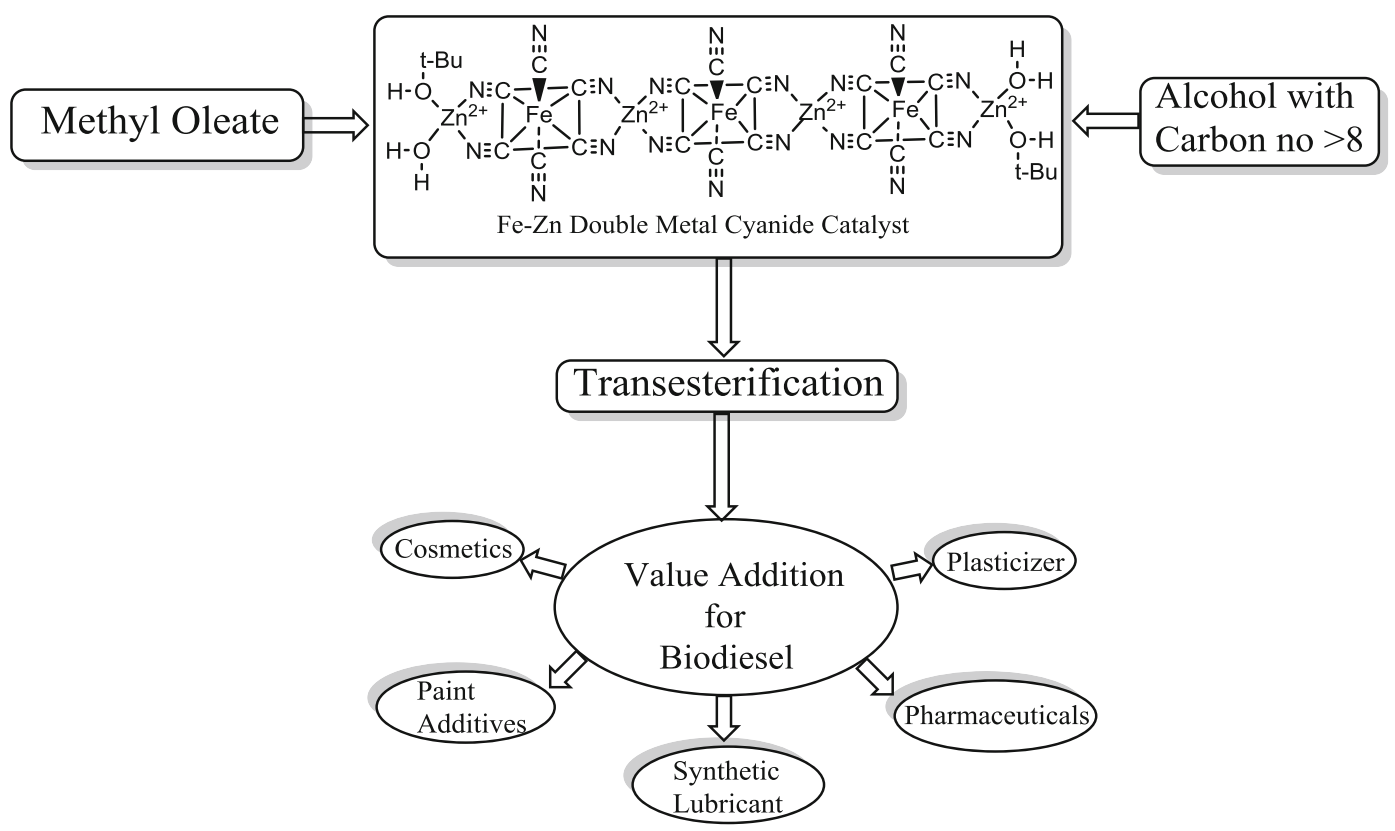

Scheme 1. Possible structure of DMC and the uses of fatty monoesters.

$\mathrm{BuOH})$ and molecular structure as shown in scheme 1) depicted XRD pattern (figure 1a) which could be indexed to a cubic lattice with a unit cell parameter of $0.904 \mathrm{~nm}$. FTIR spectrum of DMC (figure 1b) showed a characteristic band at $2096 \mathrm{~cm}^{-1}$ due to bridged cyanide group and other bands at 2925 , $1260-1450$ and $1095 \mathrm{~cm}^{-1}$ corresponding to $\mathrm{C}-\mathrm{H}$ and $\mathrm{C}-\mathrm{O}$ stretching vibrations of the coordinated tert.butanol. Nitrogen-physisorption and high resolution transmission electron microscopy (HRTEM) studies revealed that DMC is mostly microporous but has some mesoporosity of less ordered nature in its structure. ${ }^{21}$ Diffuse reflectance Fourier transform infrared (DRIFT) spectra of adsorbed pyridine and temperatureprogrammed desorption of ammonia $\left(\mathrm{NH}_{3}-\mathrm{TPD}\right)$ pointed out that it is Lewis acidic. ${ }^{19,22}$ Tetrahedrally coordinated $\mathrm{Zn}^{2+}$ are the sites of Lewis acidity which were active in transesterification reactions. ${ }^{23}$ Water adsorption studies revealed that this catalyst is hydrophobic like silicalite- $1 .{ }^{19}$ Hydrophobicity and Lewis acidity are the two unique characteristic features that differentiate DMC from several other solid acid catalysts.
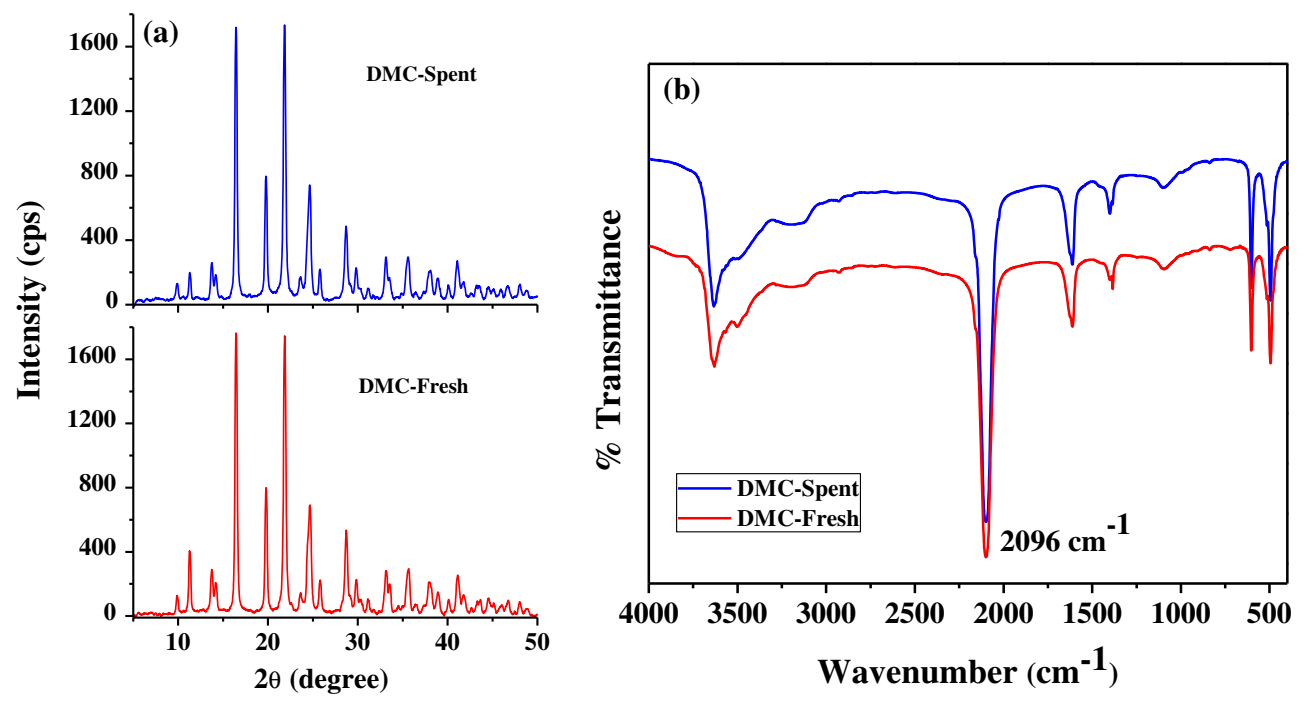

Figure 1. (a) XRD and (b) FTIR spectra of fresh and spent DMC catalysts. 

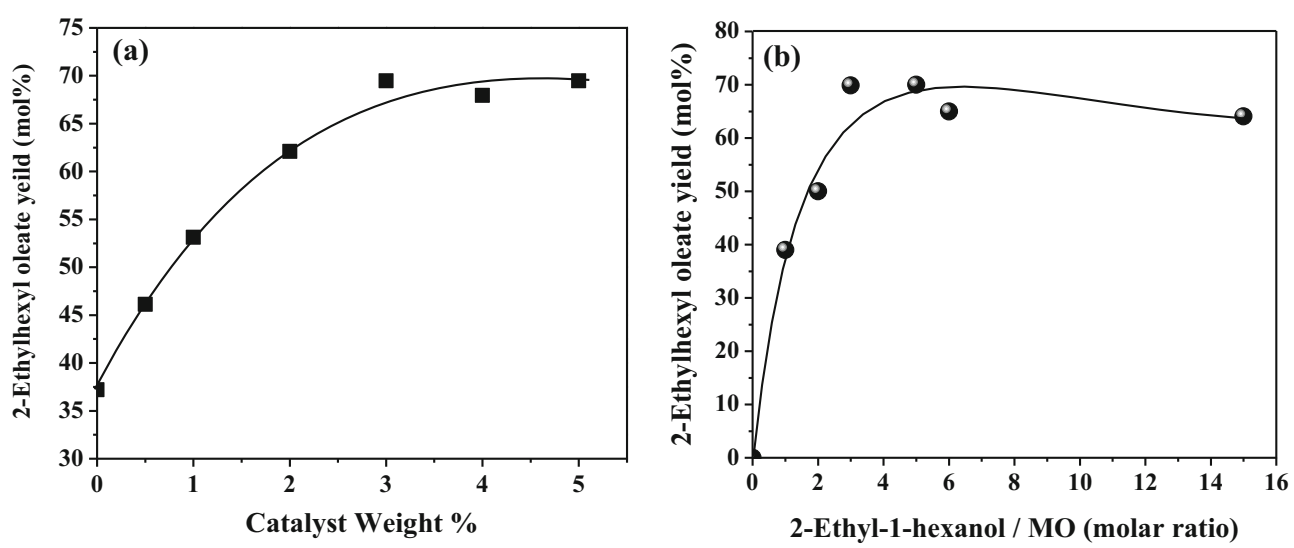

Figure 2. Effects of (a) catalyst amount and (b) 2-ethyl-1-hexanol/MO molar ratio on the yield of 2-ethylhexyl oleate. Reaction conditions: For (a): methyl oleate $(\mathrm{MO})=2 \mathrm{~g}$, 2-ethyl1 -hexanol $=2.64 \mathrm{~g}$, MO : 2-ethyl-1-hexanol (molar ratio $)=1: 3$, temperature $=180^{\circ} \mathrm{C}$, reaction time $=8 \mathrm{~h}$, pressure $=1 \mathrm{~atm}$, under a positive flow of nitrogen. For (b): $\mathrm{MO}=2 \mathrm{~g}$, $\mathrm{DMC}=3 \mathrm{wt} \%$ of $\mathrm{MO}$, temperature $=180^{\circ} \mathrm{C}$, reaction time $=8 \mathrm{~h}$, pressure $=1 \mathrm{~atm}$, under a positive flow of nitrogen.

\subsection{Catalytic activity}

Transesterification of methyl oleate (MO) with longchain monohydric alcohols (2-ethyl-1-hexanol, 1decanol and 1-dodecanol) yields fatty acid monoesters that find application not only in synthetic lubricants but in paint additives, plasticizers, pharmaceuticals and cosmetics (scheme 1). Methanol is a by-product. Formation of ethers via condensation of long-chain alcohols or methanol was not detected at our experimental conditions over DMC catalyst (HPLC, GC and ${ }^{1} \mathrm{H}$ NMR). Control experiments at $180^{\circ} \mathrm{C}$ for $8 \mathrm{~h}$ with 2ethyl-1-hexanol/MO molar ratio $=3$, revealed that this reaction occurs even in the absence of a catalyst. But the yield of 2-ethylhexyl oleate was $37 \mathrm{~mol} \%$ only (figure 2a). In presence of DMC catalyst, the yield was higher. It increased with increasing amount of the catalyst, reaching a maximum of $70 \mathrm{~mol} \%$ at a catalyst loading of $3 \mathrm{wt} \%$ of $\mathrm{MO}$ and became stable thereafter (reaction conditions: methyl oleate $(\mathrm{MO})=2 \mathrm{~g}$, 2-ethyl-1-hexanol $=2.64 \mathrm{~g}$, temperature $=180^{\circ} \mathrm{C}$ and reaction time $=8 \mathrm{~h}$ ). External mass transfer is the possible cause for this behavior at a catalyst loading above $3 \mathrm{wt} \%$. 2-Ethyl-1-hexanol/MO molar ratio had also a marked effect on the product yield (figure $2 b$ ). The yield of 2-ethylhexyl oleate increased, reached a maximum of $70 \mathrm{~mol} \%$ at a 2-ethyl-1-hexanol/MO molar ratio of 3 and decreased thereafter (reaction conditions: $180^{\circ} \mathrm{C}$, reaction time $=8 \mathrm{~h}$ and catalyst $=3 \mathrm{wt} \%$ of MO). Transesterification is an equilibrium reaction. Higher
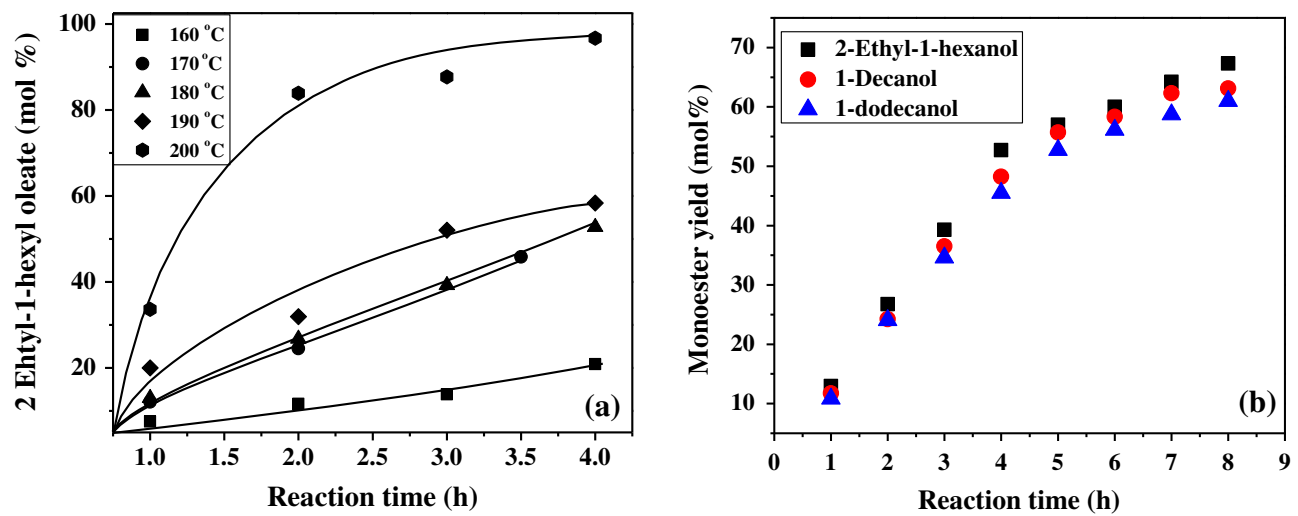

Figure 3. Effect of (a) reaction temperature and time and (b) type of long-chain alcohol on the yield of fatty monoester. Reaction conditions: For (a): methyl oleate (MO) $=2 \mathrm{~g}$, 2-ethyl-1-hexanol = 2.64 g, MO: 2-ethyl-1-hexanol (molar ratio) $=1: 3, \mathrm{DMC}=3 \mathrm{wt} \%$ of $\mathrm{MO}$, pressure $=1 \mathrm{~atm}$, under positive flow of nitrogen. For (b): $\mathrm{MO}=2 \mathrm{~g}, \mathrm{MO}$ : long-chain alcohol $($ molar ratio $)=1: 3, \mathrm{DMC}=3 \mathrm{wt} \%$ of $\mathrm{MO}$, reaction temperature $=180^{\circ} \mathrm{C}$, reaction time $=8 \mathrm{~h}$, pressure $=1 \mathrm{~atm}$, under a positive flow of nitrogen. 
amount of 2-ethyl-1-hexanol drives the equilibrium toward right, forming fatty monoester lubricant. At much higher concentrations of 2-ethyl-1-hexanol (molar ratio of 2-ethyl-1-hexanol/MO $\geq 5$ ), accessibility of MO to the active sites was low and hence, lower yields of 2-ethylhexyl oleate were obtained. Under similar experimental conditions, the product yield increased with increasing reaction time and attained equilibrium at $8 \mathrm{~h}$. Also with increasing temperature, the yield of 2-ethylhexyl oleate increased. At $180^{\circ} \mathrm{C}$ and in $4 \mathrm{~h}$, monoester yield as high as $96.7 \mathrm{~mol} \%$ was obtained (figure 3a). At high temperature, most of the known acid catalysts form ethers. The unique feature of DMC is that even at $180^{\circ} \mathrm{C}$, formation of such undesired ether products was not detected. The selectivity for the monoester and methanol were $100 \%$. DMC was reused in four recycling experiments. At the end of each run, the catalyst was separated from the reaction mixture; it was washed with methanol, dried at $100^{\circ} \mathrm{C}$ for $12 \mathrm{~h}$ and used in another recycle. The yield of 2ethylhexyl oleate was nearly the same in each recycle. XRD and FTIR spectra of the fresh and spent catalyst (at the end of 4th recycle) were almost the same (figure 1) confirming the structural integrity of DMC in transesterification runs. No leaching of metal ions was detected as revealed by atomic absorption spectroscopy (AAS). Conversion verses time plots at five different temperatures enabled rate constant and energy of activation ( $\mathrm{E}_{a}$ from the Arrhenius plot). The $\mathrm{E}_{a}$ value was determined to be $75.9 \mathrm{~kJ} / \mathrm{mol}$. Using Eyring equation enthalpy of activation $\left(\Delta \mathrm{H}^{\#}\right)$ and entropy of activation $\left(\Delta S^{\#}\right)$ were determined to be $72.3 \mathrm{~kJ} / \mathrm{mol}$ and $283.3 \mathrm{~J} / \mathrm{mol}$, respectively. As this reaction proceeds to some extent even in the absence of a catalyst, the activation energy has contributions from both thermal and catalytic reactions.

DMC is effective for transesterification of MO with different long-chain alcohols (figure 3b). A marginal decrease in equilibrium conversion of $\mathrm{MO}$ from 70 to $62 \mathrm{~mol} \%$ was observed when 1-dodecanol instead of 2ethyl-1-hexanol was used. The monoester product after removal of methanol and unreacted long-chain alcohol was pale yellow in color. Its physical properties (table 2) match well with those of hydraulic oil lubricants confirming that these long-chain alcohol fatty esters are suitable lubricant base oil. Kinematic viscosity of longchain alcohol oleates were higher than that of the starting ester (MO). As expected, 2-ethylhexyl oleate has pour point lower than the other esters and MO.

A tentative mechanism for this reaction over Lewis acidic $\mathrm{Zn}^{2+}$ active sites in DMC catalyst is shown in figure 4. Activation of $\mathrm{MO}$ at $\mathrm{Zn}^{2+}$ site; formation of carbocation; nucleophilic attack by the long-chain

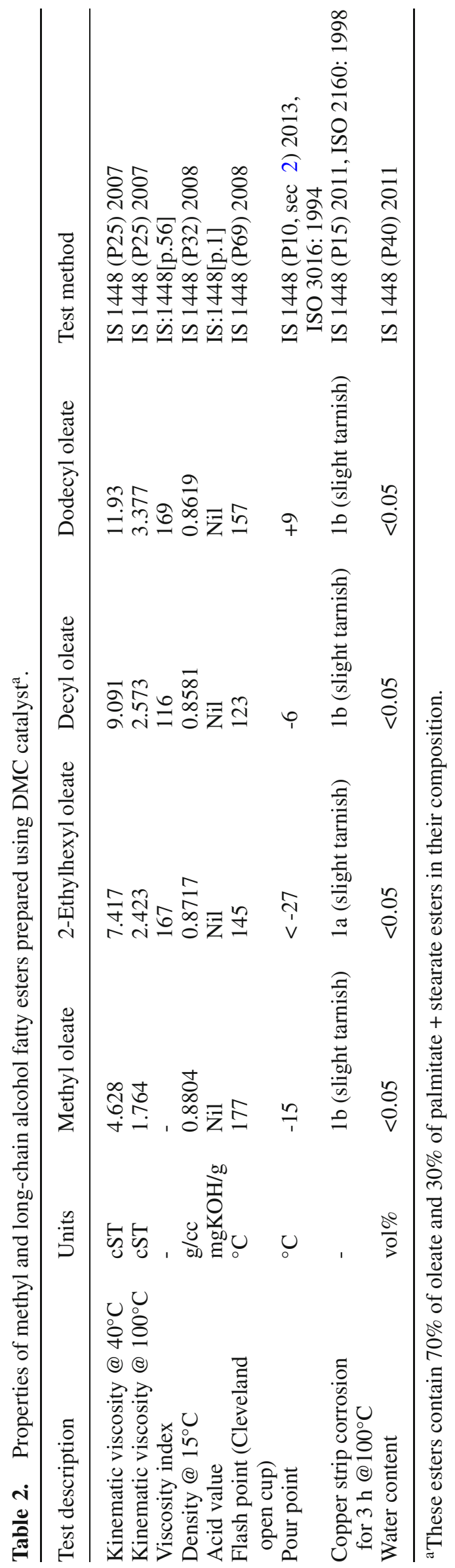




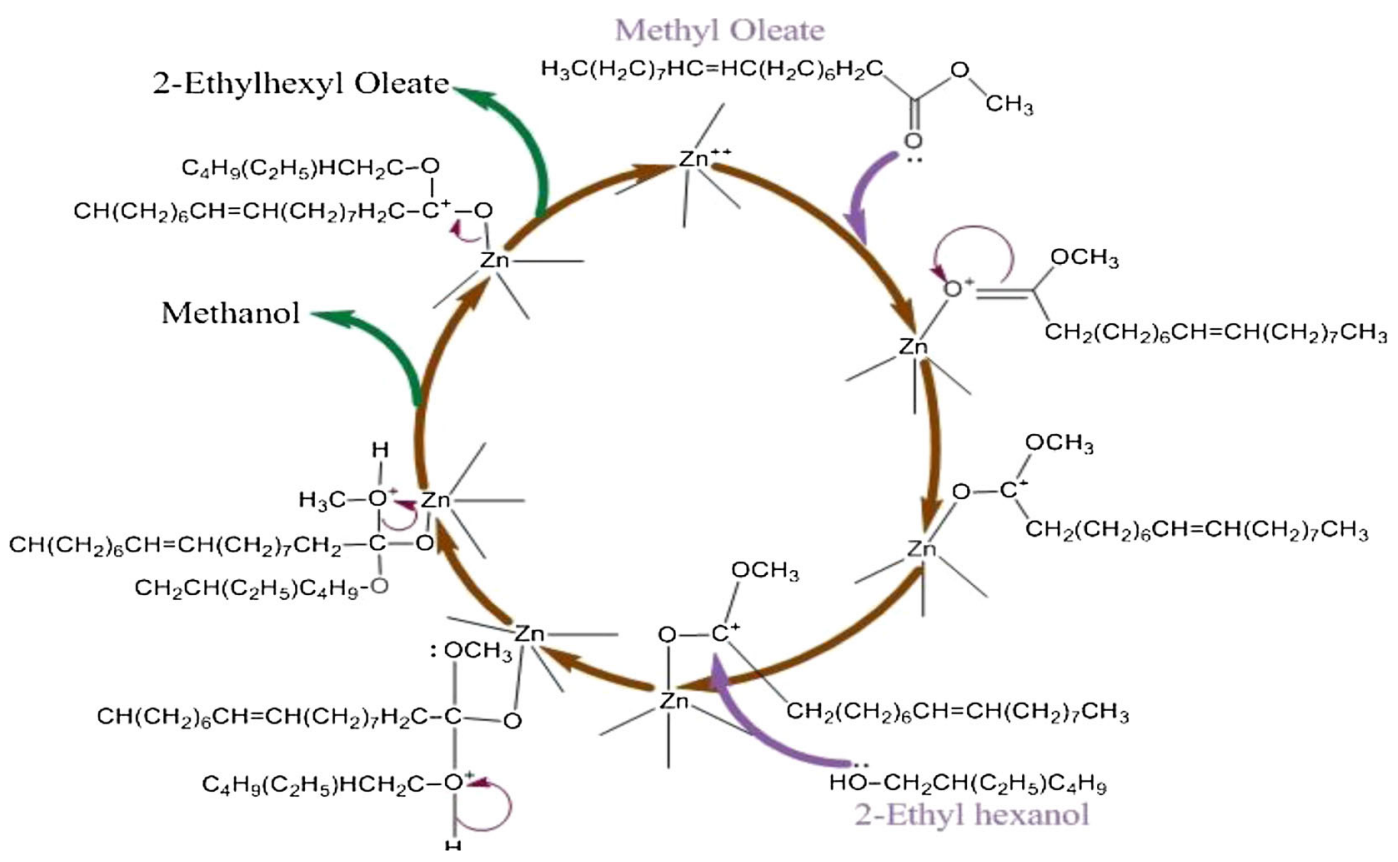

Figure 4. Tentative mechanism for the reaction of methyl oleate with 2-ethyl-1-hexanol.

alcohol (2-ethyl-1-hexanol, for example) on the carbo cation, followed by removal of methanol and long-chain alcohol oleate ester formation are the steps involved in the reaction.

\section{Conclusions}

Catalytic activity of DMC for forming fatty monoester lubricants through transesterification of methyl oleate (FAME-biodiesel) with long-chain alcohols (2-ethyl-1hexanol, 1-decanol and 1-dodecanol) was investigated. 2-Ethylhexyl oleate yield as high as $96.7 \mathrm{~mol} \%$ was achieved at $180^{\circ} \mathrm{C}$ in $4 \mathrm{~h}$. DMC was reusable in at least four recycling experiments with little loss in catalytic activity. The product long-chain alcohol ester had the desired physical properties required for lubricant applications. Fatty monoesters of long-chain alcohols were the selective products over DMC. Formation of undesired ether products were not detected even at $200^{\circ} \mathrm{C}$. Our earlier studies and this work together reveal that $\mathrm{Fe}-\mathrm{Zn} \mathrm{DMC}$ is an efficient catalyst for converting fatty compounds (vegetable oils, fatty acids and/or fatty acid methyl esters) into lubricant base oils by esterificationi/transesterification reactions.

\section{Supplementary Information}

Details on analytical studies and properties of lubricant base oil are available as supporting information in the Journal of Chemical Sciences website (www.ias.ac.in/ chemsci).

\section{Acknowledgements}

M K acknowledges the Council of Scientific and Industrial Research (CSIR), New Delhi for the award of Senior Research Fellowship. This work forms a part of the Network Project 'Catalysts for Sustainable Energy (ECat, CSC 0117)' sponsored by CSIR.

\section{References}

1. Rudnick L R 2006 Synthetics, mineral oils and biobased lubricants: chemistry and technology (Boca Raton, USA: Taylor \& Francis, CRC Press)

2. Honary L A T and Richter E 2011 Biobased lubricants and greases: Technology and products (West Sussex, UK: John-Wiley \& Sons Ltd.)

3. Bomgardner M M $2013 C \& E N$ October 2819

4. http://www.freedoniagroup.com/FreedoniaPressRelease/ World-Demand-for-Lubricants-to-Approach-42-WorldDemand-for-Lubricants-to-Approach-42-MillionMetric-Tons-in-2015.html

5. Mang T 2007 In Lubricants and lubrication (eds.) T Mang and W Dresel (Weinheim, Germany: Wiley-VCH Verlag $\mathrm{GmbH} \&$ Co. KgaA)

6. Wagner H, Luther R and Mang T 2001 Appl. Catal. A: Gen. 221429

7. Höfer R and Bigorra J 2007 Green Chem. 9203

8. Resul M F M G, Ghazi T I M and Idris A 2012 Ind. Crops Product. 3887

9. Padmaja K V, Rao B V S K, Reddy R K, Bhaskar P S, Singh A K and Prasad R B N 2012 Ind. Crops Product. 35237

10. US Patent No. $8,101,560$ B2

11. Nagendramma P 2011 Lubrication Sci. 23355

12. Madankar C S, Dalai A K and Naik S N 2013 Ind. Crops Product. 44139 
13. Åkerman C O, Gaber Y, Ghani N A, Lämsä M and HattiKaul R 2011 J. Mol. Catal. B: Enz. 72263

14. Oh J, Yang S, Kim C, Choi I, Kim J H and Lee H 2013 Appl. Catal. A: Gen. 455164

15. Masood H, Yunus R, Choong T S Y, Rashid U and Taufiq Yap Y H 2012 Appl. Catal A: Gen. 425-426 184

16. Santacesaria E, Martinez Vicente G, Di Serio M and Tesser R 2012 Catal. Today 1952

17. Kotwal M, Kumar A and Srinivas D 2013 J. Mol. Catal: Chem. 37765
18. Varhadi P, Kotwal M and Srinivas D 2013 Appl. Catal. A: Gen $\mathbf{4 6 2} 129$

19. Sreeprasanth P S, Srivastava R, Srinivas D and Ratnasamy P 2006 Appl. Catal. A: Gen. 314148

20. Kotwal M, Deshpande S S and Srinivas D 2011 Catal. Commun. 121302

21. Sebastian J and Srinivas D 2011 Chem. Commun. 47 10449

22. Satyarthi J K and Srinivas D 2010 Energy Fuel 242154

23. Srivastava R, Srinivas D and Ratnasamy P 2006 J. Catal. 24134 